\title{
STUDY COMPARING CORONARY STENTING IN SMALLER VESSELS VERSUS LARGE VESSELS
}

\author{
Harish Oruganti, Indrani Garre, Bharathi Vanaparty, SreekanthYerram
}

\section{ABSTRACT:}

Background: Smaller vessel PTCA account to approximately on third of all PTCA worldwide. With increasing incidence of diabetes mellitus and aging, this proportion can increase considerably. This is a region of interest for us because Indians, in particular, are known to have smaller coronaries. There are limited studies in coronary vessels $<2.5$ are available. Most of the previous studies defined small vessel as $<3$ or $2.75 \mathrm{~mm}$.

Methods and Results: This is an observational single center study where we analyzed 650 patients, 52 in the small vessel group $(<2.5 \mathrm{~mm})$ and 598 in large vessel group $(\geq 2.5 \mathrm{~mm})$ with similar mean age between the both the groups $(57.5 \pm 11.4$ vs $57.9 \pm 11.1 \mathrm{yrs})$. Hypertension and smoking are more in large vessel group $(74.7 \%$ vs $61.9, p=0.004 ; 22.1 \%$ vs $13.4 \%, p=0.007)$, whereas no difference for presence of diabetes (54.2\% vs $54.3 \%$ ) or type of CAD (CSA - chronic stable angina $-70.3 \%$ vs $76.1 \%$, $p=0.2$ ). Large vessel group patients had more $L V$ dysfunction $(40.3 \%$ vs $24.6 \%, p=0.000)$.

Mean Pre reference diameter was $1.9 \pm 0.5 \mathrm{~mm}$ in small vessel group versus $2.9 \pm 0.5 \mathrm{~mm}$ in large vessel group. Mean minimum lesion diameter in small vessel group is $0.8 \pm 0.3 \mathrm{~mm}$ versus $1.3 \pm 1.9 \mathrm{~mm}$ in large vessel group. Mean pre-lesion length is $16.7 \pm 3.5 \mathrm{~mm}$ in small vessel group versus $18.3 \pm 8.3 \mathrm{~mm}$ in large vessel group. Mean stent size is $2.33 \mathrm{~mm}$ in small vessel group versus $3.04 \mathrm{~mm}$ in large vessel group. Mean stent length is $17.27 \mathrm{~mm}$ in small vessel group versus $21.8 \mathrm{~mm}$ in large vessel group. The success of PCI in small vessel group was $96 \%$ (not able to deliver stent in one patient and in one patient there was a non-flow limiting distal stent dissection) and $98 \%$ in large vessel group.

In one year follow-up, 5 (3.5\%) patients from small vessel group and $34(4.5 \%)$ patients from large vessel group had MACCE which is not statistically significant $(p=0.6)$

Conclusions: Small vessel (really small means less than 2.5 mm) PCI, not only acute but also one-year results are good with MACCE rate of $3.5 \%$ and comparable to large vessel PCI.

Keywords: Small Coronaries, Percutaneous Coronary Interventions.

Article received on 01 JAN 2017, published on 31JAN 2017.

Harish Oruganti1, ,Indrani Garre ${ }^{2}$, Bharthi Vanaparty ${ }^{3}$, Sreekanth Yerram ${ }^{3}$

${ }^{1}$ Senior Resident, Department of Cardiology, NIMS, India

${ }^{2}$ PhD Student, Department of Cardiology, NIMS, India

${ }^{3}$ Asst.Professor,Departmet of Cardiology, NIMS, India

${ }^{3}$ Asst.Professor,Departmet of Cardiology, NIMS, India

Corresponding author: Harish Oruganti

Email: harishoruganti@yahoo.com

\section{INTRODUCTION:}

Percutaneous transluminal coronary angioplasty with stenting is an established treatment for patients with symptomatic coronary artery disease [1,2].More than a third of coronary lesions treated with angioplasty are estimated to be in vessels smaller than $3.0 \mathrm{~mm}$ (in a few studies, it is almost about 50\%[3,4].With increasing aging population and with the increasing incidence of diabetes mellitus, this proportion is likely to increase further. The topic of small vessel stenting is of importance for us, as Indians are believed to have smaller coronary arteries and increasing diabetics. Most studies that have documented the benefit of elective stent implantation following angioplasty, including the BENESTENT $^{1}$ and STRESS ${ }^{2}$ trials, had excluded lesions in vessels with a diameter of less than $3.0 \mathrm{~mm}$. Therefore, stenting is generally recommended as a treatment option only for larger vessels. ${ }^{3}$ Analyses after PTCA have generally shown an inverse relationship between vessel size and severity of angiographic restenosis at follow-up[5,6]. (PCI) of small vessels has historically been associated with high rates of acute vessel closure, restenosis, target lesion revascularization (TLR), and stent thrombosis, particularly in diabetic patients $[7,8,10]$ The purpose of the present study is to analyze the outcomes and various factors associated with smaller vessel $(<2.5 \mathrm{~mm}$ diameter) coronary stenting.

\section{METHODS:}

This is an observational single center study where we analyzed the PCI patient details over two-year period at Nizam's institute of medical sciences, Hyderabad, Telangana, India.

Evaluation of data on stenting in this subgroup of patients is complicated by the fact that studies have used different criteria to define "small" coronary artery. The upper cut-off for reference vessel diameter has varied from 2.5 to $3.0 \mathrm{~mm}$. Earlier studies had mostly defined vessels $<3 \mathrm{~mm}$ as small vessels which may not be true in Indians scenario. We have taken a cut off value of $2.5 \mathrm{~mm}$. Patients with a lesion with core laboratory- 
measured RVD $\leq 2.25 \mathrm{~mm}$ was defined as the small vessel group, while those with an RVD $>2.5 \mathrm{~mm}$ were defined as the large vessel group. Patients with multiple lesions treated during the procedure were categorized accordingly. Target lesion failure (TLF) was defined as cardiac death, target vessel myocardial infarction, and clinically driven TLR. Major adverse cardiac events (MACE) were defined as all-cause death, myocardial infarction, emergent coronary artery bypass surgery, or repeat clinically indicated target lesion percutaneous or surgical revascularization. Target vessel failure (TVF) was defined as cardiac death, myocardial infarction, or clinically driven TVR by percutaneous or surgical methods. Clinically driven TLR (and TVR) was defined as revascularization at the target lesion (and target vessel) associated with positive functional ischemia study or ischemic symptoms and an angiographic minimal lumen diameter stenosis $\geq 50 \%$ by quantitative coronary angiography, or revascularization of a target lesion with diameter stenosis $\geq 70 \%$ by quantitative coronary angiography without either angina or a positive functional study. Stent thrombosis was defined as Academic Research Consortium (ARC) definite or probable stent thrombosis [9].

Institutional ethics committee approval was taken and we collected clinical, demographic and PCI details of all these patients. All these patients were followed for one year either clinically or telephonically.

The study population comprised all 650 patients, 52 in the small vessel group $(<2.5 \mathrm{~mm})$ and 598 in large vessel group ( $\geq 2.5 \mathrm{~mm}$ ) from Nizam's institute of medical sciences, with successful stent placement (stent at the desired position, residual stenosis $<30 \%$ ) during the period from May 2013 through may2015. Excluded from the study were patients with cardiogenic shock or mechanical ventilation before PTCA.

All patients received $5000 \mathrm{U}$ of heparin and $325 \mathrm{mg}$ of aspirin with $300 \mathrm{mg}$ of clopidogrel or other antiplatelet according to Mehran bleeding risk score before PTCA.

Adequacy of the result was based solely on visual assessment of the stent site in the angiogram; Standardized image acquisition was used, consisting of multiple projections for each lesion, accurately reproduced in each angiographic session. Quantitative analysis was performed on the baseline angiogram, on that containing the maximally inflated balloon, and on final post stenting angiogram.

\section{Statistical Analyses:}

Statistical analysis was performed with SPSS statistical software. The study population was subdivided into 2 groups according to $\mathrm{RD}$; the ranges were $<2.5 \mathrm{~mm}$ for the first group, $>2.5 \mathrm{~mm}$ for the second. Continuous parameters are presented as mean \pm standard deviation and compared using the t-test or Wilcoxon rank-sum test as appropriate. Nominal parameters are presented as percentages and compared using Fisher's exact test. Multivariate logistic regression was used to assess the independent role of vessel size in restenosis after adjustment for other covariates. Differences were statistically significant when the respective $\mathrm{P}$ values were $<0.05$.

\section{RESULTS:}

Of 650patients, 52 were in the small vessel group $(<2.5$ $\mathrm{mm}$ ) and 598 were in large vessel group ( $\geq 2.5 \mathrm{~mm})$.

Mean age was similar between both the groups (57.5 \pm 11.4 vs $57.9 \pm 11.1$ yrs.). Percentage of females was significantly higher in the small vessel group (31(59.6\%) compared to large vessel group 197(32.9\%), $\mathrm{p}=0.001$.

Table 1 shows that hypertension and smoking were found to be more common in large vessel group $(74.7 \%$ vs $61.9 \%, \mathrm{p}=0.004 ; 22.1 \%$ vs $13.4 \%$, $\mathrm{p}=0.007)$, but there was no difference for presence of diabetes $(54.2 \%$ vs $54.3 \%$ ) or type of CAD (CSA -chronic stable angina $70.3 \%$ vs $76.1 \%$, $p=0.2$ ) between the two groups. Large vessel group patients had more LV dysfunction. (40.3\% vs $24.6 \%, \mathrm{p}=0.000)$. There was no difference in anthropometric parameters like height weight or BMI between the two groups as shown in table 2 .

Table 1: Baseline demographic patient characteristics in small vessel and large vessel groups

\begin{tabular}{|l|l|l|l|}
\hline Variable & $\begin{array}{c}\text { Small } \\
\text { Vessel }\end{array}$ & $\begin{array}{l}\text { Large } \\
\text { Vessel }\end{array}$ & $\begin{array}{l}\mathrm{p} \\
\text { value }\end{array}$ \\
\hline Number of patients & 52 & 598 & \\
\hline Age (Mean \pm SD) & $57.5 \pm 11.4$ & $57.9 \pm 11.1$ & 0.72 \\
\hline Sex (Females) & $31(59.6 \%)$ & $197(32.9 \%)$ & 0.000 \\
\hline Hypertension (\%) & $61.97 \%$ & $74.7 \%$ & 0.004 \\
\hline Diabetes (\%) & $54.2 \%$ & $54.3 \%$ & 0.98 \\
\hline Smoker (\%) & $13.4 \%$ & $21.1 \%$ & 0.007 \\
\hline LV dysfunction (\%) & $24.7 \%$ & $40.3 \%$ & 0.000 \\
\hline $\begin{array}{l}\text { Multi Vessel } \\
\text { Disease (\%) }\end{array}$ & $20.4 \%$ & $37.8 \%$ & 0.000 \\
\hline
\end{tabular}


Table 2: Comparison of clinical parameters between two groups

\begin{tabular}{|l|l|l|l|l|l|}
\hline \multirow{2}{*}{ Variable } & \multicolumn{2}{|c|}{ Small Vessel } & \multicolumn{2}{c|}{ Large Vessel } & \\
\cline { 2 - 5 } & Mean \pm SD & Median & Mean \pm SD & Median & p value \\
\hline SBP $(\mathrm{mm} \mathrm{Hg})$ & $152.16 \pm 70$ & 150 & $149.28 \pm 75$ & 150 & 0.37 \\
\hline DBP $(\mathrm{mm} \mathrm{Hg})$ & $75.14 \pm 40$ & 80 & $76.01 \pm 40$ & 70 & 0.83 \\
\hline Height $(\mathrm{cm})$ & $160.68 \pm 140$ & 161 & $159.61 \pm 118$ & 160 & 0.30 \\
\hline Weight $(\mathrm{kg})$ & $64.8 \pm 36$ & 64 & $63.66 \pm 35$ & 62 & 0.39 \\
\hline BMI $\left(\mathrm{kg} / \mathrm{m}^{2}\right)$ & $24.50 \pm 18.37$ & 24.387 & $24.71 \pm 19.78$ & 24.242 & 0.30 \\
\hline
\end{tabular}

SBP: systolic blood pressure, DBP: diastolic blood pressure, BMI: body mass index Pre-ref: pre-reference vessel diameter, Pre-MLD: pre-minimal lumen diameter, Post-MLD: post minimal lumen diameter.

Table 3 shows that mean Pre-reference diameter was $1.9 \pm 0.89 \mathrm{~mm}$ in small vessel group versus $2.42 \pm 0.33 \mathrm{~mm}$ in large vessel group. Mean minimum lumen diameter in small vessel group is $0.8 \pm 0.36 \mathrm{~mm}$ versus $1.3 \pm 1.9 \mathrm{~mm}$ in large vessel group. Smaller vessel group has shorter length and fewer multivessel involvements compared to larger vessel group. Mean pre-lesion length is $16.7 \pm 3.5$ $\mathrm{mm}$ in small vessel group versus $18.3 \pm 8.3 \mathrm{~mm}$ in large vessel group. Mean stent size is $2.23 \mathrm{~mm}$ in small vessel group versus $3.04 \mathrm{~mm}$ in large vessel group. Mean stent length is $17.27 \mathrm{~mm}$ in small vessel group versus $21.8 \mathrm{~mm}$ in large vessel group. Success of PCI in small vessel group was $96 \%$ (not able to deliver stent in one patient and in one patient there was a no flow limiting distal stent dissection) and $98 \%$ in large vessel group.

Table 3: Comparison of angiographic characteristics of the two groups

\begin{tabular}{|l|l|l|l|l|l|}
\hline \multirow{2}{*}{ Angiographic parameters } & \multicolumn{2}{|c|}{ Small Vessel } & \multicolumn{2}{c|}{ Large Vessel } & \multirow{2}{*}{ p value } \\
\cline { 2 - 6 } & Mean \pm St Dev & Median & Mean \pm St Dev & Median & 0.000 \\
\hline Pre-ref & $1.97 \pm 0.89$ & 1.89 & $2.42 \pm 0.33$ & 2.395 & 0.56 \\
\hline Pre-MLD & $0.85 \pm 0.36$ & 0.79 & $1.32 \pm 0.08$ & 1.05 & 0.004 \\
\hline Pre-lesion length & $16.77 \pm 0.78$ & 5.58 & $18.33 \pm 0.85$ & 7.555 & 0.55 \\
\hline Pre-stenosis (\%) & $57.62 \pm 32$ & 56.5 & $58.67 \pm 13$ & 57 & 0.99 \\
\hline Post-ref & $2.42 \pm 1.46$ & 2.2 & $2.79 \pm 1.65$ & 2.69 & 0.56 \\
\hline Post MLD & $1.91 \pm 1.03$ & 1.91 & $2.35 \pm 0.48$ & 2.29 & 0.069 \\
\hline Post stenosis (\%) & $17.38 \pm 6$ & 15 & $15.20 \pm 1$ & 14 & 0.000 \\
\hline stent size & $2.230 \pm 2$ & 2.25 & $3.04 \pm 2.5$ & 3 & 0.001 \\
\hline stent length & $17.28 \pm 10$ & 16 & $21.81 \pm 6$ & 19 & 0.000 \\
\hline Multi Vessel Disease (\%) & $20.4 \%$ & & $37.8 \%$ & & \\
\hline
\end{tabular}

\section{DISCUSSION:}

The relationships among stenosis severity, lesion length, and trans-lesional flow in an idealized system are governed by Poiseuille's law, which dictates that flow varies directly as a function of luminal diameter and inversely as a function of lesion length: 
in which $\Delta \mathrm{P}$ is the pressure difference across the stenosis, $\mathrm{r}$ is the minimal lumen radius of the stenotic segment, $\eta$ is blood viscosity, and 1 is the length of the lesion[11]. Because flow across the lesion varies in proportion to the fourth power of radius but only as the first power of length, lesion length would be expected to exert a relatively little impact on trans-lesional flow for discrete (e.g., $<5 \mathrm{~mm}$ long) stenosis.

It is essential that physicians performing coronary angiography or angioplasty understand this basic concept [12].

Thus, the vessel radius has a greater impact on the vessel flow. Poiseuille's law relates to flow of fluids through cylindrical tubes in well-controlled experimental settings. It does not take into consideration complexities of human coronary artery disease (CAD) such as plaque irregularity and eccentricity, nonlaminar and pulsatile flow, vasoactive properties of the arterial wall, and the potential for compensatory dilation.There are certain procedural issues involving small vessel stenting that needs to be discussed.

These are:

(i) Difficulty in reaching the lesion site as small vessels tend to be peripheral and the stent may have to pass through several bends and curves before reaching the site. Therefore, the primary success rate of stenting such arteries may not be as high as that of larger vessels, especially if the stents used are not tracked able and flexible.

(ii) The chances of stent dislodgement are higher as stents may need to be placed in distal lesions after passing through a small and tortuous vessel. But with the availability of balloon-mounted stents, this is usually not a major problem.

(iii) The choice of stent itself may be an issue since routine stents deployed in small coronary vessels have a higher metal-to-artery ratio. This may increase the risk of subsequent problems such as subacute thrombosis and restenosis[13].

For small vessel treatment, stent implantation was not demonstrated to be superior to balloon angioplasty, therefore, small vessel stent implantation was a controversial issue in the bare metal stent (BMS) era[14,16] C-SIRUIS and E-SIRIUS evaluated the efficacy of sirolimus-eluting stent (SES) implantation for diffuse long and small vessel disease $[17,18]$.
Procedural success rates in our study were $96 \%$ and $98 \%$ in small and large vessel groups respectively. This is in concordance with studies by Lau et al and Morice etal. According to Lau etal, early, and long-term results in 197 consecutive patients who underwent stent implantation in 207 vessels with a diameter $<3.0 \mathrm{~mm}$ the procedural success rate was $97.3 \%$, lesion severity reduced from $85 \pm 9 \%$ to $3 \pm 7 \%$, with a subacute stent thrombosis rate of $0.5 \%$. Survival without major target lesion-driven events was $77 \%$ and $74 \%$ at 1 and 2 years of follow-up, respectively. The 6-month angiographic restenosis rate was $30.1 \%$. Diabetes mellitus, small vessel size and stent size $<2.7 \mathrm{~mm}$ were found to be independent predictors of in-stent restenosis. In a similar study, Morice et al.20 reported that among 190 patients stented with $2.5 \mathrm{~mm}$ stents, the procedural success rate was $98 \%$, subacute thrombosis rate was $2.6 \%$ and repeat intervention rate on follow-up was $24.5 \%$. Thus, several non-randomized trials of small vessel stenting have been reported. The initial procedural success rate ranged from $93 \%$ to $98 \%$, subacute thrombosis rate from $0.5 \%$ to $3.8 \%$ and the restenosis rate from $21 \%$ to $36 \%$. Adverse clinical events ranged from $11 \%$ to $26 \%$.

The initial and long-term success rates of stenting in small coronary vessels were nearly the same as those for large vessel stenting in this era when mostly second generation DES is used $[19,20,21]$. These studies conclusively established the feasibility, safety, and efficacy of small vessel stenting, especially in situations where balloon angioplasty results were suboptimal (provisional stenting). Results from our study also reflect similar finding.

\section{LIMITATIONS:}

It is an observational single center study the results of which cannot be extrapolated to all the patient population. Operator skill and experience may have influenced the outcome of this study. Attempts were made to limit confounding using propensity matching in a multivariable analysis; however, this approach cannot entirely eliminate residual confounding of unmeasured factors. IVUS could not be performed in our study due to logistic concern. Various clinical and biological factors may theoretically modify the influence of vessel size on late angiographic outcome and deserve evaluation in 
future studies. However, it is worth noting that although some clinical factors have been found to be independently correlated with luminal re-narrowing (e.g., diabetes and type and duration - angina before angioplasty, which was not analyzed in detail in this study.

\section{CONCLUSION:}

This study shows that demographic parameters may not significantly influence the outcome in small vessel stenting. Further studies need to evaluate these findings in Indian population. Small vessel (less than $2.5 \mathrm{~mm}$ ) PCI has good immediate procedural and one year outcome and with a less MACE rate of 3.5\% (2 TLR,1 MI,1 CABG, 0TLF) i.e., comparable to large vessel PCI.

Conflicts of interest: None

\section{REFERENCES:}

1. Serruys PW, de Jaegere P, Kiemeneij F, Macaya C, Rutsch W, Heyndrickx G, Emanuelsson H, Marco J, Legrand V, Materne P, Belardi J, Sigwart U, Colombo A, Goy JJ, van den Heuvel P, Delcan J, Morel MA. A comparison of balloon-expandable-stent implantation with balloon angioplasty in patients with coronary artery disease: Benes tent Study Group. N Engl J Med. 1994; 331:489-495.

2. Fischman DL, Leon MB, Baim DS, Schatz RA, Savage MP, Penn I, Detre K, Veltri L, Ricci D, Nobuyoshi M, Cleman M, Heuser R, Almond D, Elezi et al November 3, 1998, 1879 by guest on December 11, 2016, http://circ.ahajournals.org/ Downloaded from Teirstein PS, Fish RD, Colombo A, Brinker J, Moses J, Shaknovich A, Hirshfeld J, Bailey S, Ellis S, Rake R, Goldberg S. A randomized comparison of coronary-stent placement and balloon angioplasty in the treatment of coronary artery disease: Stent Restenosis Study Investigators. N Engl J Med. 1994;331:496-501.

3. Savage MP, Fischman DL, Rake R, Leon MB, Schatz RA, Penn I, et al. Efficacy of coronary stenting versus balloon angioplasty in small coronary arteries. Stent Restenosis Study (STRESS) Investigators. J Am Coll Cardiol 1998; 31: 307-311.
4. Akiyama T, Moussa I, Reimers B, Ferraro M, Kobayashi Y, Blengino S, et al. Angiographic and clinical outcome following coronary stenting of small vessels: a comparison with coronary stenting of large vessels. J Am Coll Cardiol 1998; 32: 1610-1618.

5. Hirshfeld JW, Schwartz SS, Jugo R, Macdonald RG, Goldberg S, Savage MP, Bass TA, Vetrovec G, Cowley M, Taussig AS, With worth HB, Margolis JR, Hill JA, Pepine CJ. Restenosis after coronary angioplasty: a multivariate statistical model to relate lesion and procedural variables to restenosis. J Am Coll Cardiol. 1991;18:647-656.

6. Foley DP, Melkert R, Serruys PW. Influence of coronary vessel size on narrowing process and late angiographic outcome after successful balloon angioplasty. Circulation. 1994;90:1239-1251.

7. Moreno R, Fernandez C, Alfonso F, Hernandez R, Perez Vizcayno MJ, Escaned J, Sabate M, Banuelos C, Angiolillo DJ, Azcona L, Macaya C. Coronary stenting versus balloon angioplasty in small vessels: a metaanalysis from 11 randomized studies. J Am Coll Cardiol. 2004;43:1964-72.

8. Suselbeck T, Latsch A, Siri H, Gonska B, Poerner T, Pfleger S, Schumacher B, Borggrefe M, Haase KK. Role of vessel size as 1221EuroIntervention 2016;12:1215-1221 Resolute ZES in extra-small vessels a predictor for the occurrence of in-stent restenosis in patients with diabetes mellitus. Am J Cardiol. 2001;88:243-7.

9. Cutlip DE, Windecker S, Mehran R, Boam A, Cohen DJ, van Es GA, Steg PG, Morel MA, Mauri L, Vranckx P, McFadden E, Lansky A, Hamon M, Krucoff MW, Serruys PW; Academic Research Consortium. Clinical end points in coronary stent trials: a case for standardized definitions. Circulation. 2007;115: 2344-51.

10. Moer R, Myreng $\mathrm{Y}$, Albertsson $\mathrm{P}$, Gunnes $\mathrm{P}$, Lindvall B, Wiseth $\mathrm{R}$, et al. Stenting in small coronary arteries (SISCA): a randomized comparison of heparin coated be Stent and balloon angioplasty (Abstr). J Am Coll Cardiol 2001; 37: 46A.

11. Berne R, Levy M: Cardiovascular physiology, St Louis, 1986, Mosby. 
12. Marcus M, Harrison D, White $C$, et al: Assessing the physiologic significance of coronary obstructions in patients: Importance of diffuse undetected atherosclerosis. Prog Cardiovasc Dis 31:39-56, 1988.

13. Bahl, V. K., and R. Narang. "Elective stenting in small coronary arteries: lessons learnt from recent trials." Indian heart journal 53.3 (2001): 275-281.

14. Hirshfeld JW, Schwartz JS, Jugo R, et al, the MHEART Investigators: Restenosis after coronary angioplasty: A multivariate statistical model to relate lesion and procedure variables to restenosis. J Am Coll Cardiol 18:647-656, 1991.

15. Elezi S, Kastrati A, Neumann FJ, et al: Vessel size and long-term outcome after coronary stent placement. Circulation 98:1875-1880, 1998.

16. Akiyama T, Moussa I, Reimers B, et al: Angiographic and clinical outcome following coronary stenting of small vessels: A comparison with coronary stenting in large vessels. J Am Coll Cardiol 32: 16101618, 1998.

17. Schofer J, Schluter M, Gershlick $A H$, et al: Sirolimus-eluting stents for treatment of patients with long atherosclerotic lesions in small coronary arteries: Double-blind, randomized controlled trial (E-SIRIUS). Lancet 362:1093-1099, 2003.
18. Schampaert E, Cohen EA, Schlüer $M$, et al: The Canadian Study of the Sirolimus-Eluting Stent in the Treatment of Patients with Long De Novo Lesions in Small Native Coronary Arteries (C-SIRIUS). JACC 43:1110-1115, 2004

19. Caputo, R., Leon, M., Serruys, P., Neumann, F. J., Yeung, A, Windecker, S \& Saito, S. (2014). Performance of the resolute zotarolimus-eluting stent in small vessels. Catheterization and Cardiovascular Interventions, 84(1), 17-23.

20. Her miller, James B., et al. "Clinical outcomes in real-world patients with small vessel disease treated with XIENCE $V ®$ everolimus-eluting stents: One year results from the XIENCE V® USA condition of approval post-market study." Catheterization and Cardiovascular Interventions 84.1 (2014): 7-16.

21. Saito, Shigeru, et al. "Clinical and angiographic evaluation of the resolute zotarolimus-eluting coronary stent in Japanese patients." Circulation Journal79.1 (2014): 96-103. 